\title{
Análise microclimática de manguezais em Unidades de Conservação de Proteção Integral e de Uso Sustentável
}

\author{
Emerson Galvani ${ }^{(\mathrm{a})}$; Nádia Gilma Beserra de Lima ${ }^{(\mathrm{b})}$; Marília Cunha-Lignon ${ }^{(\mathrm{c})}$ \\ (a) Professor do Departamento de Geografia, Faculdade de Filosofia, Letras e Ciências Humanas, Universidade de \\ São Paulo, egalvani@usp.br \\ (b) Geógrafa e Especilaista Ambiental, Secretaria do Meio Ambiente do Estado de São Paulo, \\ nadiagilma@yahoo.com.br \\ (c) Professora do Curso de Engenharia de Pesca, Universidade Estadual Paulista, Câmpus Experimental de Registro, \\ SP, cunha.lignon@registro.unesp.br
}

Eixo: Climatologia em diferentes níveis escalares: mudanças e variabilidades

\begin{abstract}
Resumo/
Os manguezais ocorrem ao longo de gradientes ambientais em diferentes escalas de atuação. Entender as respostas ecofisiológicas dos manguezais diante desses gradientes é de suma importância para sua conservação. No litoral sul de São Paulo, o microclima vem sendo estudado como um indicador de alterações que estão ocorrendo na estrutura do manguezal, em sua borda e no interior de seu ecossistema. O presente trabalho apresenta análise e comparação dos atributos climáticos temperatura do ar, radiação solar e precipitação em manguezais do litoral sul do estado de São Paulo, em Unidades de Conservação de Uso Sustentável e de Proteção Integral: Área de Proteção Ambiental CananéiaIguape-Peruíbe (APACIP) e Parque Estadual da Ilha do Cardoso (PEIC), repectivamente. Constatouse que as UCs de Proteção Integral tem papel fundamental na manutenção do bom estado de conservação dos manguezais do litoral sul de São Paulo e consequentemente de seus serviços ecossistêmicos relacionados à estabilização do microclima.
\end{abstract}

Palavras chave: atributos climáticos, mangue, áreas protegidas, monitoramento

\section{Introdução}

Os manguezais estão distribuídos na zona intertidal, nas regiões tropicais e subtropicais no intervalo de, aproximadamente, $30^{\circ} \mathrm{N}$ e $30^{\circ} \mathrm{S}$ de latitude. Sua distribuição global é delimitada pelas grandes correntes oceânicas e a isoterma de $20{ }^{\circ} \mathrm{C}$ da água do mar no inverno (ALONGI, 2009). Esse ecossistema representa a interface entre sistemas terrestres e marinhos, que recebem entrada diária de água do mar (marés), de água doce, sedimentos e nutrientes.

Para Lugo et al. (2014), os manguezais ocorrem ao longo de gradientes ambientais em diferentes escalas de atuação. Respondem globalmente aos gradientes de temperatura latitudinais, enquanto localmente, os gradientes de salinidade do substrato tem maior destaque. Portanto, entender as respostas ecofisiológicas dos manguezais a diferentes gradientes ambientais é essencial, considerando as diferentes escalas de análise. Esse conhecimento é de suma importância para a conservação desse ecossistema. 
Esse ambiente contribui com a estabilização da linha de costa e reduz o impacto de fenômenos extremos, como em tempestades, furacões e tsunamis (LACAMBRA et al., 2008, ALONGI, 2008, KRAUSS et al., 2009, ZHANG et al., 2012; MCLVOR et al., 2012).

O Brasil possui a terceira maior área de manguezal do mundo (GIRI et al., 2011). De acordo com Magris; Barreto, (2010), no Brasil, os manguezais apresentam um nível elevado de proteção com aproximadamente $83 \%$ de sua cobertura vegetal localizada dentro de áreas protegidas. Ao se considerar as áreas instituídas pelos três entes do governo (federal, estadual e municipal), 77\% dos manguezais sob proteção estão situadas em áreas protegidas em categorias de Uso Sustentável. Além disso, os manguezais são protegidos por lei federal e são designados como Áreas de Preservação Permanente por meio do Código Florestal. Os autores ressaltam que esforços na implementação destas áreas devem ser realizados, como forma de garantir uma gestão sustentável dos recursos provenientes dos manguezais.

No entanto, apesar desse alto índice de instrumentos de conservação, os manguezais têm apresentado alterações significativas oriundas da influência antrópica no ambiente (VALIELA et al., 2001; ALONGI, 2002), principalmente os localizados em Unidades de Conservação de Uso Sustentável, como as APAs. As áreas de manguezais são cada vez menores e/ou fragmentadas, provocando a perda de seus serviços ecossistêmicos e benefícios ao longo do tempo (DUKE, et al. 2007).

Essas modificações alteram a cobertura vegetal, que por sua vez, influenciam todo o ecossistema instalado, inclusive as interações microclimáticas (GALVANI; LIMA, 2010; MEDELLU et al., 2012, LIMA et al., 2013). Diante disso, o microclima pode ser um indicador de que alterações estão ocorrendo no manguezal, tanto em sua borda quanto em seu interior. No entando, os efeitos de atributos climáticos (radiação solar, chuva, evaporação, temperatura do ar, umidade e vento) são, muitas vezes, negligenciados nos estudos sobre os manguezais e, com isso, os processos atmosféricos que operam acima dos manguezais têm sido pouco estudados (MAZDA; WOLANSKI; RIDD, 2007).

No litoral sul de São Paulo, monitoramento integrado dos manguezais tem sido realizado com uso de imagens de satélite, parcelas permanentes e análise microclimática o qual tem fornecido subsídios para gestão desse trecho da zona costeira (CUNHA-LIGNON et al., 2015). O microclima vem sendo estudado como um indicador de que alterações estão ocorrendo na estrutura do manguezal, em sua borda e no interior de seu ecossistema. Aliado a isso, o estudo das variáveis microclimáticas pode ainda contribuir para a compreensão da importância dos manguezais em caso de tempestades e eventos extremos em uma escala local (GALVANI; LIMA, 2010; BESERRA DE LIMA; GALVANI, 2013, LIMA et al., 2013).

Assim, o presente trabalho apresenta análise e comparação dos atributos climáticos temperatura do ar, radiação solar e precipitação em manguezais do litoral sul do estado de São Paulo, em Unidades de 


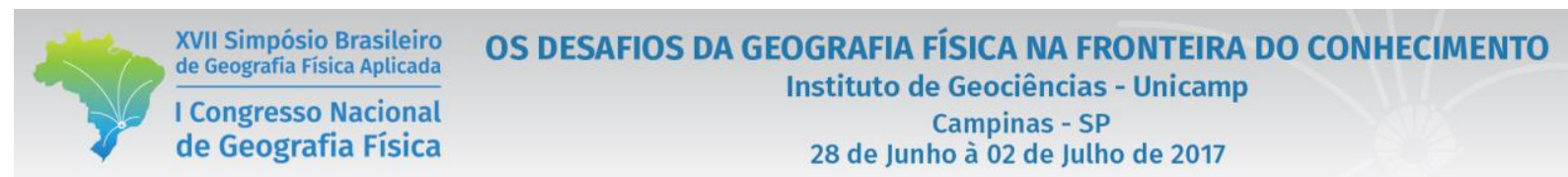

Conservação de Uso Sustentável e de Proteção Integral: Área de Proteção Ambiental Cananéia-IguapePeruíbe (APACIP) e Parque Estadual da Ilha do Cardoso (PEIC), repectivamente.

\section{2. Área de Estudo}

Os manguezais aqui estudados estão localizados no Sistema Costeiro de Cananéia-Iguape, considerado uma das áreas costeiras mais conservadas do Estado de São Paulo, devido à sua extensão e estágio de conservação (CUNHA-LIGNON et al., 2011).

Apesar da conservação da região, estudos apontam para ocorrência de clareiras em áreas de mangue na região de Iguape, devido ao aumento de macrófitas aquáticas invasoras nesse setor, resultado da abertura do canal do Valo Grande (CUNHA-LIGNON et al., 2011). A abertura desse canal artificial ocorreu entre 1827 e 1852 e causou mudanças significativas tanto na salinidade e nos padrões de sedimentação, quanto no aporte de metais pesados para o Sistema Costeiro Cananéia-Iguape (MAHIQUES et al., 2009). A Figura 1 apresenta a distribuição dos manguezais e macrófitas no Sistema Costeiro Cananéia-Iguape.

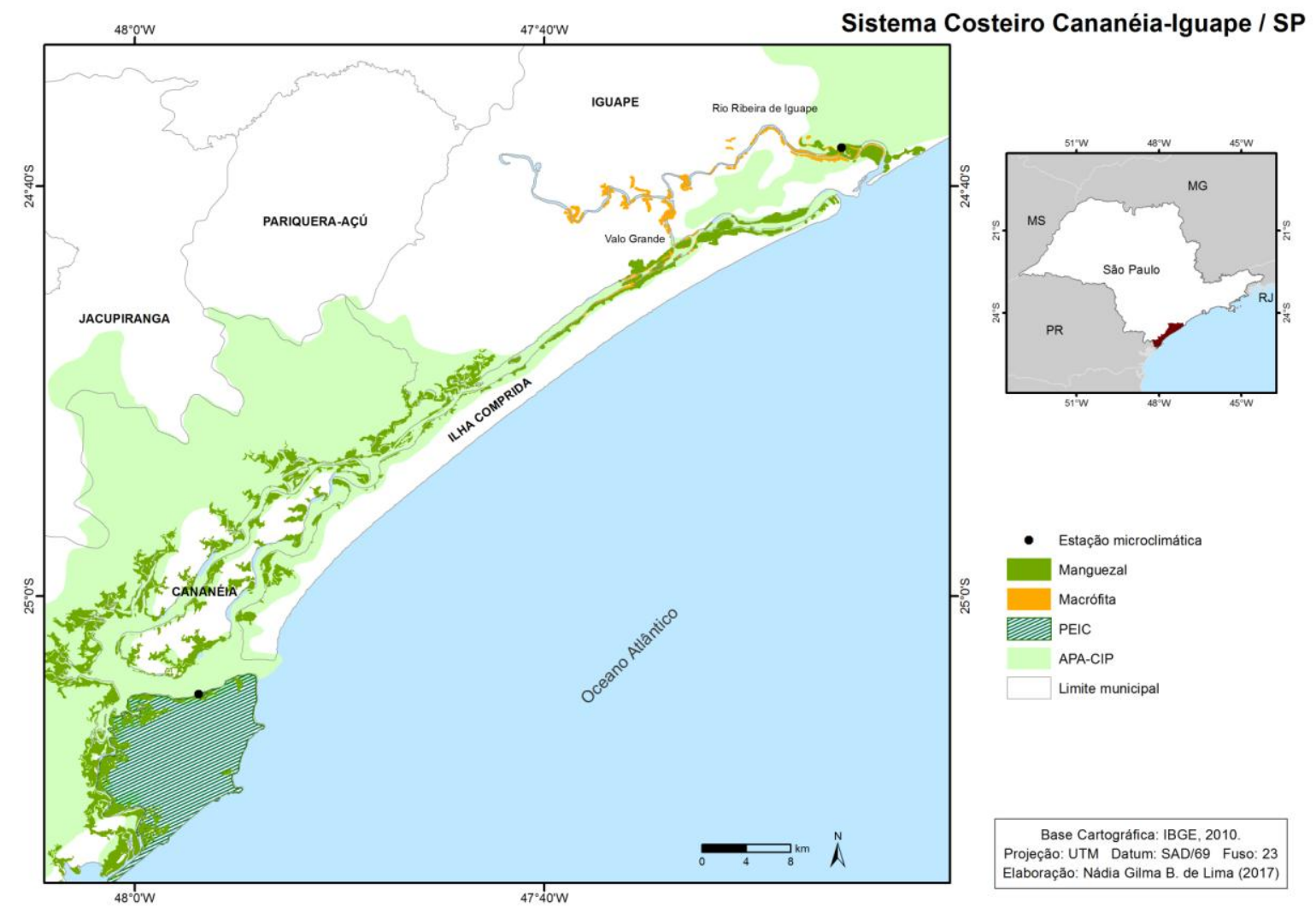

Figura 1 - Distribuição dos manguezais no Sistema Costeiro Cananéia-Iguape, localização das estações meteorológicas automáticas e das Unidades de Conservação de Proteção Ambiental Cananéia-Iguape -Peruíbe (APA-CIP) e Parque Estadual da Ilha do Cardoso. Fonte: Cunha-Lignon et al. (2011). 
A Área de Proteção Ambiental Cananéia-Iguape-Peruíbe (APACIP) criada pelo Decreto $N^{\circ}$ 90.347, de 1984, e ampliada pelo Decreto No 91.892, de 1985, é uma Unidade de Conservação federal de uso sustentável, sob tutela do Instituto Chico Mendes de Conservação da Biodiversidade. O Parque Estadual da Ilha do Cardoso (PEIC) foi criado em 1962 pelo Decreto Estadual No 40.319 e está sob os cuidados da Fundação Florestal, vinculada à Secretaria do Meio Ambiente do Estado de São Paulo.

\section{Procedimentos Metodológicos}

No setor norte do sistema costeiro Canánéia-Iguape, na Barra do Ribeira, onde localiza-se parte da APACIP, o levantamento microclimático foi iniciado em 2008, com a instalação de uma torre microclimática, contendo duas estações meteorológicas automáticas (EMA), de forma a efetuar análises da variação vertical dos atributos climáticos e da influência do dossel de manguezal no microclima. A torre microclimática apresenta uma estação meteorológica localizada a $2 \mathrm{~m}$ de altura em relação à superfície, contendo sensores de temperatura do ar, umidade relativa do ar, direção e velocidade do vento, precipitação e radiação solar global, visando obter os dados com a influência do dossel. A torre microclimática possui também outra estação meteorológica instalada de forma a ultrapassar o dossel da vegetação, com o intuito de registrar os atributos climáticos antes da interferência da vegetação, com $12 \mathrm{~m}$ de altura em relação a superfície, com obtenção dos mesmos atributos climáticos, além de um saldoradiômetro, para obtenção do Saldo de Radiação no ambiente. Os equipamentos são programados para registro a cada 10 minutos.

No setor sul, onde localiza-se o PEIC, foi instalada uma EMA em 2011. A estação encontra-se a 2 m de altura do solo, contendo sensores de temperatura do ar, umidade relativa do ar, direção e velocidade do vento, radiação solar global e pluviosidade. A seguir são apresentadas as análises dos atributos climáticos monitorados nos bosques nas UCs de Uso Sustentável (APACIP) e de Proteção Integral (PEIC). Os atributos apresentados serão temperatura do ar (01/10/2011 a 30/04/2015), radiação solar (01/10/2011 a 29/05/2013)e precipitação (01/10/2011 a 31/11/2012). Os períodos de análise para cada atributo são diferentes devido a falhas técnicas de alguns equipamentos ao longo do período de monitoramento. No entorno, de ambas as EMAs foram instaladas parcelas permanentes nos bosques de mangue, onde é monitorada de estrutura vegetal e a ocorrência de vegetação associada, de acordo com metodologia proposta por Schaeffer-Novelli e Cintrón (1986). 
XVII Simpósio Brasileiro

de Geografia Física Aplicada

I Congresso Nacional

de Geografia Física
OS DESAFIOS DA GEOGRAFIA FÍSICA NA FRONTEIRA DO CONHECIMENTO

Instituto de Geociências - Unicamp

Campinas - SP

28 de Junho à 02 de Julho de 2017

\section{Resultados e discussão}

Comparando-se o desenvolvimento estrutural de bosques de mangue em área conservada na UC de Proteção Integral (PEIC) e alterada na UC de Uso Sustentável (APACIP), pode-se afirmar que em ambas as áreas domina a espécie vegetal típica de mangue, denominada mangue vermelho, Rhizophora mangle. No setor conservado, o bosque é caracterizado por apresentar recrutamento de plântulas e de indivíduos jovens. Enquanto que na área alterada não há recrutamento de plântulas e a espécie mangue branco, Laguncularia racemosa, com DAP (diâmetro a altura do peito) entre $2,5 \mathrm{~cm}$ e $10 \mathrm{~cm}$, apresenta $28 \%$ de troncos mortos. O bosque de mangue em área alterada é caracterizado por presença de espécies associadas, tais como Acrostichum aureum (samabaia do mangue) e macrófitas aquáticas, indicando alteração no ambiente (LIMA et al., 2013).

A comparação dos ambientes considerados conservados localizados no PEIC e alterados na APACIP são trabalhados adotando as seguintes premissas:

$\checkmark$ - O clima regional em ambos os bosques de mangue (conservado e alterado) pode ser considerado uniforme dentro dos limites da área de estudo.

$\checkmark$ - A distância entre as Estações Meteorológicas Automáticas (EMAs) aproximados $70 \mathrm{~km}$ em um alinhamento NE-SW, não representam diferenças significativas nos atributos climáticos em uma escala climática de análise regional.

$\checkmark$ - A EMA instalada no manguezal alterado da APACIP, mesmo distante 4,3 $\mathrm{km}$ da linha de costa, não sobre influência, significativa dos efeitos de continentalidade.

- A EMA instalada no manguezal conservado do PEIC próximo a orla, contudo em condição sotavento da Ilha do Cardoso, também não apresenta efeito de sombra de chuva oriundas do relevo da área de estudo.

$\checkmark \quad$ - Os resultados serão discutidos sempre considerando o manguezal conservado como referência.

Considera-se, portanto, que as diferenças encontradas nos atributos climáticos (temperatura do ar, umidade relativa do ar, precipitação, radiação solar global, direção e velocidade - media e rajada - dos ventos) são influenciados diferentemente pelo dossel da vegetação do mangue e consequentemente seu estado de conservação. A interação da radiação solar - fluxos de entrada e saída de energia - são condicionados pelos aspectos estruturais do dossel do bosque de mangue em função de: área foliar, índice de área foliar, espécies, estrutura, dominância, abertura do dossel, entre outros aspectos fitossociológicos do manguezal. A seguir, é apresentada uma caracterização geral da temperatura do ar, da precipitação e do vento registrados nos dois bosques. 


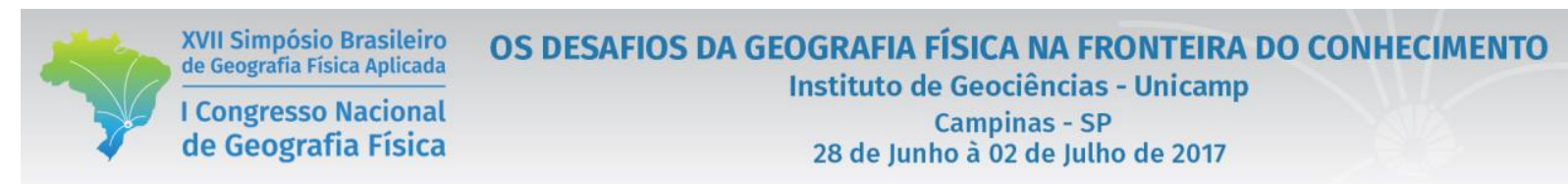

Temperatura do ar: Considerando o banco de dados registrado nos manguezais no período analisado, observa-se que a maior temperatura absoluta registrada ocorreu em dezembro/2012, com $39,1^{\circ} \mathrm{C}$ no mangue alterado da APACIP e $36,6^{\circ} \mathrm{C}$ no conservado do PEIC. Essa diferença entre os bosques conservado e alterado está associada a estrutura do dossel, mais densa no bosque conservado, impedindo a entrada de parte da energia no sistema. Outro mês que merece destaque refere-se a setembro/2012, com a maior diferença entre os bosques considerando a máxima absoluta na escala diária, $\operatorname{com} 7,2^{\circ} \mathrm{C}$ superior no mangue alterado.

Por outro lado, o menor valor registrado ocorreu em julho/2013, com os sensores apresentando $7,2^{\circ} \mathrm{C}$ no mangue alterado e $6,7^{\circ} \mathrm{C}$ no mangue conservado, o que evidencia uma diferença de $1,9^{\circ} \mathrm{C}$. Ainda considerando as diferenças entre os dois bosques de mangue estudados, vale destacar que para a temperatura mínima, diferentemente da máxima, a maior diferença encontrada entre os dois bosques foi $4,2^{\circ} \mathrm{C}$, mas com o bosque conservado sendo superior ao registro do bosque alterado.

A maior diferença entre os dois pontos ocorreu no dia 23/03/2014, com diferença positiva de $1,9^{\circ} \mathrm{C}$. Por outro lado, no dia 20/07/2012 essa diferença foi de $-2,2^{\circ} \mathrm{C}$, ou seja, com temperatura do bosque conservado superior ao do alterado. Os valores médios diários acabam por mascarar variações em escala de tempo menor, como na variação horária da temperatura média, em que em alguns instantes essas diferenças chegaram a $11,3^{\circ} \mathrm{C}$ positivos, em que a temperatura do mangue alterado é superior ao mangue conservado, e em outro instante essa diferença foi de $-8,4^{\circ} \mathrm{C}$, quando a temperatura do mangue conservado foi superior a do mangue alterado. Quanto as mínimas absolutas, destaca-se, assim como na temperatura média, valores superiores no mangue conservado, com diferença de até $2,9^{\circ} \mathrm{C} \mathrm{a}-4,2^{\circ} \mathrm{C}$ entre os bosques de mangue. A tabela I apresenta a síntese dos valores de temperatura do ar e suas derivadas.

Tabela I - Síntese dos valores máximos, mínimos e médios e amplitudes térmicas nos dois bosques de mangue: alterado e conservado.

\begin{tabular}{|l|c|c|c|c|c|c|}
\hline \multirow{2}{*}{} & \multicolumn{3}{|c|}{$\begin{array}{c}\text { Valores } \\
\text { médios }\left({ }^{\circ} \mathrm{C}\right)\end{array}$} & \multicolumn{2}{c|}{$\begin{array}{c}\text { Valores } \\
\text { absolutos }\left({ }^{\circ} \mathrm{C}\right)\end{array}$} & \multirow{2}{*}{ Amplitude } \\
\cline { 2 - 6 } & $\mathrm{T}_{\max }$ & $\mathrm{T}_{\min }$ & $\mathrm{T}_{\operatorname{med}}$ & $\mathrm{T}_{\max }$ & $\mathrm{T}_{\min }$ & \\
\hline Alterado & 26,5 & 18,7 & 22,1 & 39,1 & 7,2 & 31,8 \\
\hline Conservado & 25,8 & 19,5 & 22,4 & 36,6 & 6,7 & 29,9 \\
\hline Desvio & 0,7 & $-0,8$ & $-0,3$ & 2,5 & 0,5 & \\
\hline
\end{tabular}

Os resultados indicam que as amplitudes foram menores no bosque conservado, apresentando menor variação na temperatura do ar (Figura 2). O bosque alterado apresentou valores mais baixos para as temperaturas mínimas e os valores mais elevados para temperaturas máximas. Durante o dia, o dossel aberto permite que mais energia atinja e aqueça o substrato do manguezal. Durante o período noturno, 
copas abertas, de dossel menos denso, facilitam maior perda de energia do ambiente para a atmosfera potencializando as amplitudes térmicas e os valores absolutos de temperatura mínima do ar.

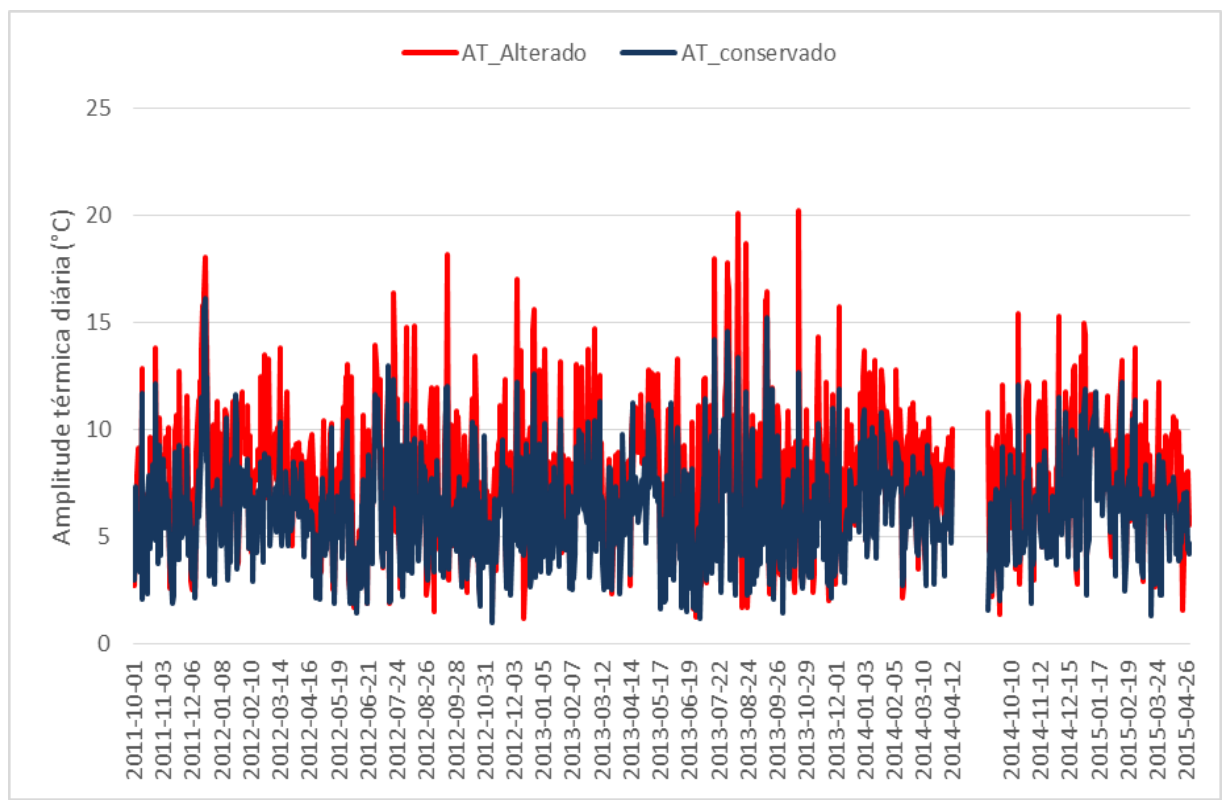

Figura 2 - Amplitude térmica diária nos bosques alterado e conservado.

Radiação Solar Global: A média diária de radiação solar global abaixo do dossel, a 2 metros (RG2), no bosque de mangue alterado, da APACIP, foi de 4,8 MJ.m ${ }^{-2}$. O valor máximo diário de radiação solar global ocorreu no dia 07/01/2013, com 11,3 MJ.m-2 . Enquanto no bosque conservado, do PEIC, o valor máximo registrado ocorreu em 31/10/2012 e foi de 6,5 MJ.m-2 ${ }^{2}$ A radiação solar global média para o bosque conservado foi de 2,9 MJ.m-2 ${ }^{2}$ O menor registro ocorreu no dia 26/04/2012, apenas 0,2 MJ.m-2

Comparando os dois bosques de mangue, verificou-se que os valores no bosque conservado apresentam-se mais reduzidos do que no bosque alterado. A figura 3 apresenta a variação da radiação solar global nos dois bosques no período de 01/10/11 a 29/05/13. Observa-se um ciclo sazonal condicionado ao nível energético desta latitude ao longo dos anos. É possível perceber que os valores acompanham a declinação solar, ou seja, nos meses do ano em que o sol declina para o hemisfério sul (setembro a março) os valores de radiação solar atingem seus valores mais elevados e, por outro lado, nos meses em que o sol encontrase com declinação positiva (hemisfério norte entre os meses de abril a agosto) observam-se valores mais reduzidos de temperatura do ar. Isso demonstra que o microclima experimentado por esses ambientes estão condicionados a controles de escala maior, como a latitude e a declinação solar.

Constatou-se que a amplitude da radiação solar global no período, foi superior no bosque de mangue alterado, da APACIP. Enquanto a amplitude no manguezal conservado foi de 6,31 MJ.m-2 , no bosque

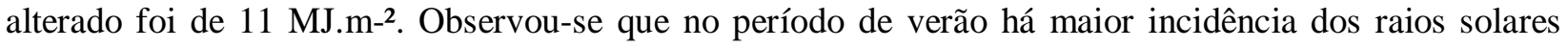




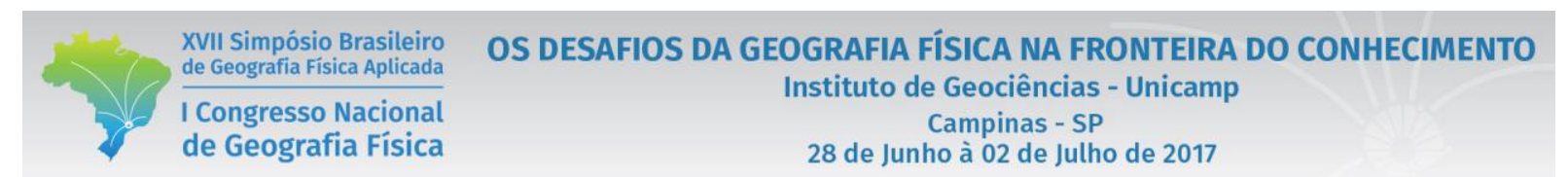

dentro do bosque alterado do que nas outras estações do ano, enquanto no bosque de mangue conservado, do PEIC, apesar dessa variação ser perceptível, a uma menor variação na quantidade incidente de radiação solar entre o verão e o inverno, o que torna o ambiente menos sujeito a variações da temperatura do ar ao longo do período. Destaca-se ainda uma maior variabilidade dos dados no bosque de mangue alterado.

Para identificar se os dados obtidos nos dois bosques apresentavam diferenças significativas, os mesmos foram submetidos a teste de normalidade. Com a aplicação do teste, constatou-se que os dados em análise diária não apresentaram distribuição normal ( $p<0,005$ ), o que implicou na aplicação do teste de hipótese Wilcoxon, em nível de 5\% de significância. Nesse caso, comparando os dados da radiação solar global obtida no mangue alterado e no conservado, constatou-se que são significativamente diferentes.

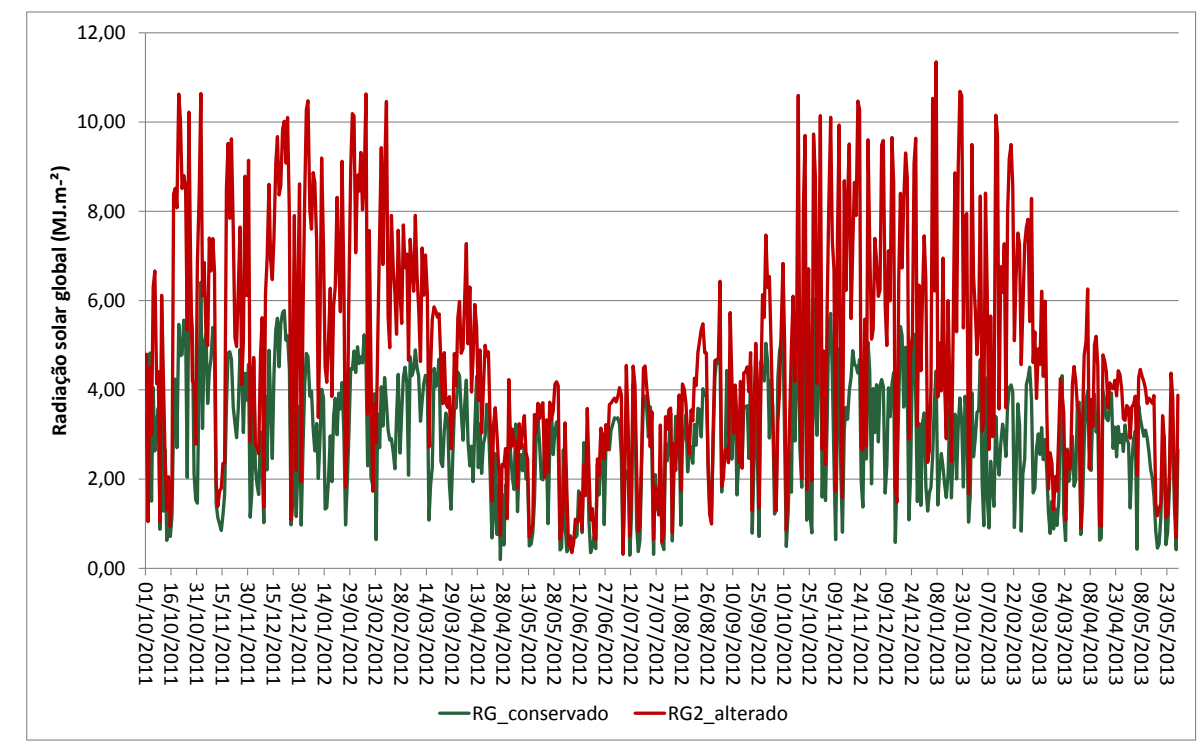

Figura 3 - Radiação solar global a 2 metros no bosque alterado e no conservado, no período de 01/10/11 a 29/05/13. Aplicando a correlação de Pearson, observa-se que há uma alta correlação entre os dados, com coeficiente de correlação (R) de 0,783. A figura 4 apresenta as regressões lineares obtidas para a adiação solar nos dois bosques analisados. 


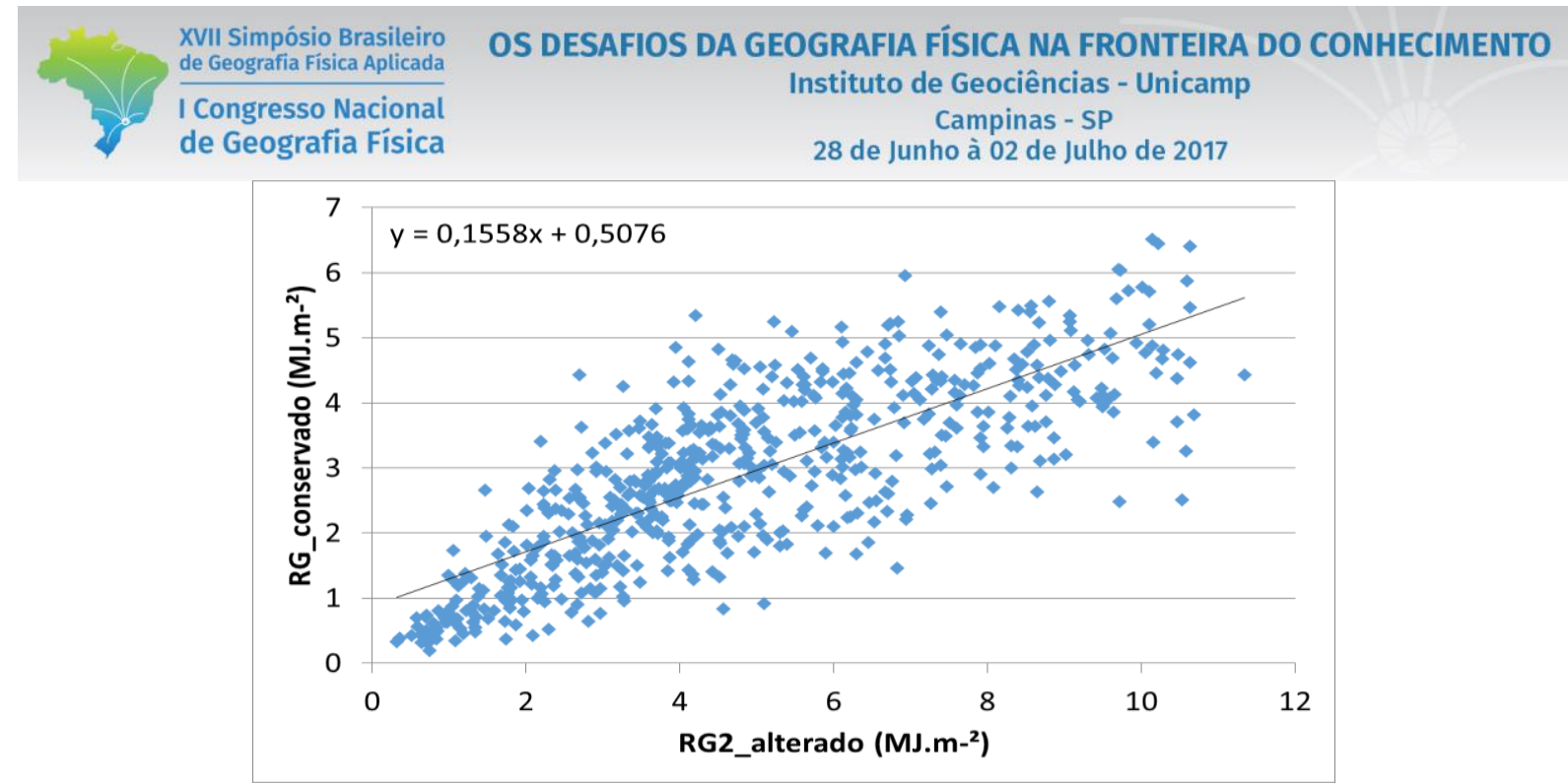

Figura 4 - Regressão linear entre a radiação solar global abaixo do dossel do mangue alterado e conservado, no período de 01/10/11 a 29/05/13.

Precipitação: Ao longo do período de 01/10/2011 a 31/11/2012, o sensor instalado no manguezal alterado, da APACIP, registrou 1.994,3 mm, enquanto no manguezal conservado, do PEIC, foi registrado o valor de 1.717,9 mm (Figura 5). Ao analisar os dados mensais de precipitação, o mês de junho se destacou como o mês com maior acumulado no bosque alterado, com 356,8 mm. O que de acordo com Tarifa (2004) isso reflete um ano atípico, visto que o esperado é janeiro ser considerado o mais chuvoso da região. No bosque de mangue conservado, o mês com maior total acumulado foi janeiro de 2012 com registro de $248,8 \mathrm{~mm}$.

Quanto ao máximo diário precipitado nos dois bosques de mangue, o alterado registrou um valor de 100 mm no dia 25/12/2011, enquanto no conservado o máximo precipitado em 24 horas ocorreu no dia 15/03/2012, em que foram registrados $155,0 \mathrm{~mm}$. Essa diferença de totais diários e datas de ocorrência está associado com a gênese das precipitações que ocorrem na região nesse período do ano, que se caracterizam por processos convectivos, localizados, de curta duração e intensidade elevada. Quanto ao número de dias com chuva, esse valor foi bem próximo nos dois bosques, de um total de 427 dias, no bosque alterado 209 dias foi registrado algum tipo de precipitação enquanto no bosque conservado foram 208 dias com precipitação.

A figura 6 apresenta a relação entre a precipitação nos manguezais conservado e alterado. Observa-se que o acumulado registrado nos dois bosque quando representados em um gráfico de dispersão se afastam da linearidade, e principalmente no período de 15/03/2012 a 07/06/2012 há um distanciamento maior dos dados em relação a linha de tendência. Nesse período as precipitações registradas no bosque conservado foram superiores àquelas ocorridas no bosque alterado. 


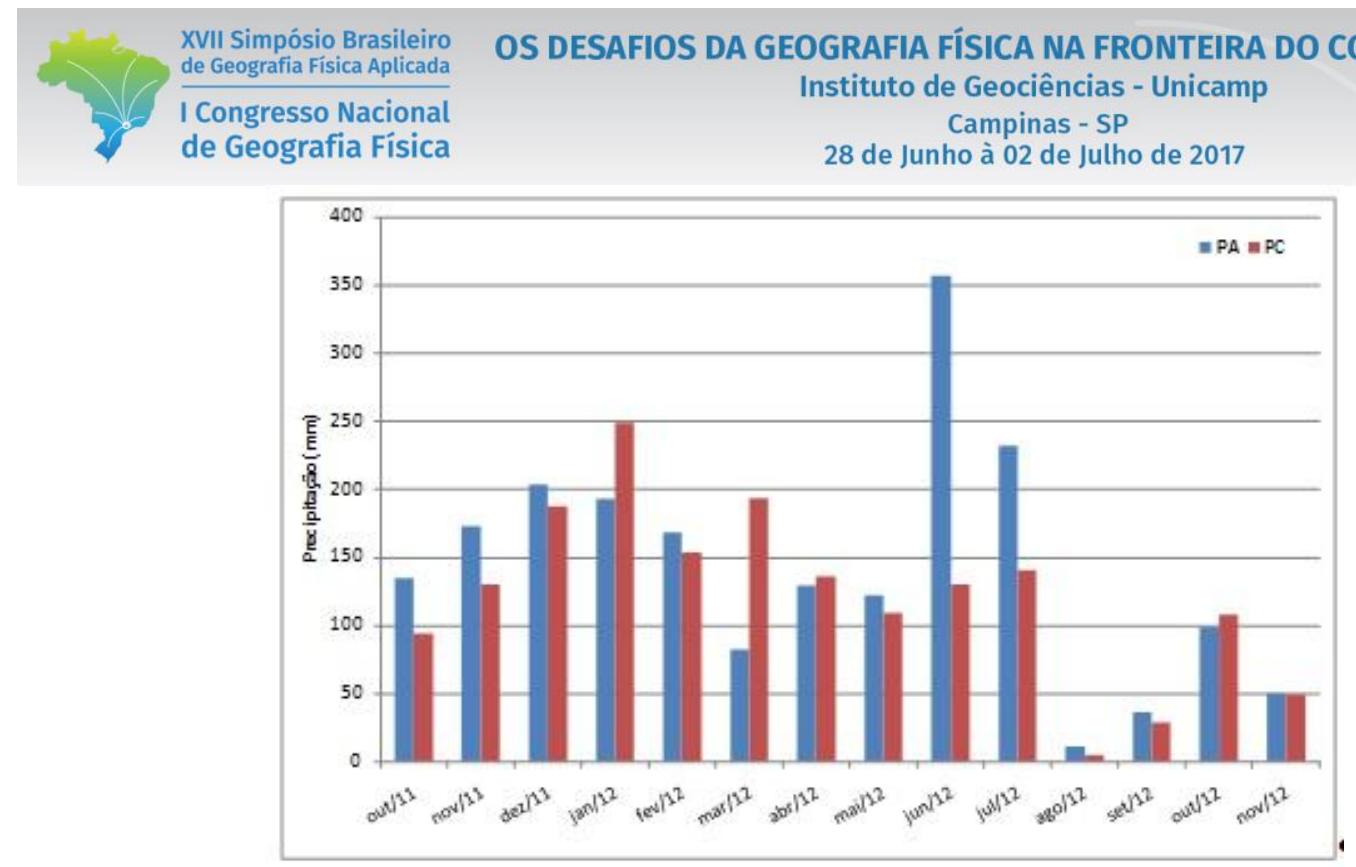

Figura 5. Precipitação mensal registrada nos bosques de mangue alterado (PA), na APACIP, e conservado (PC), no PEIC.

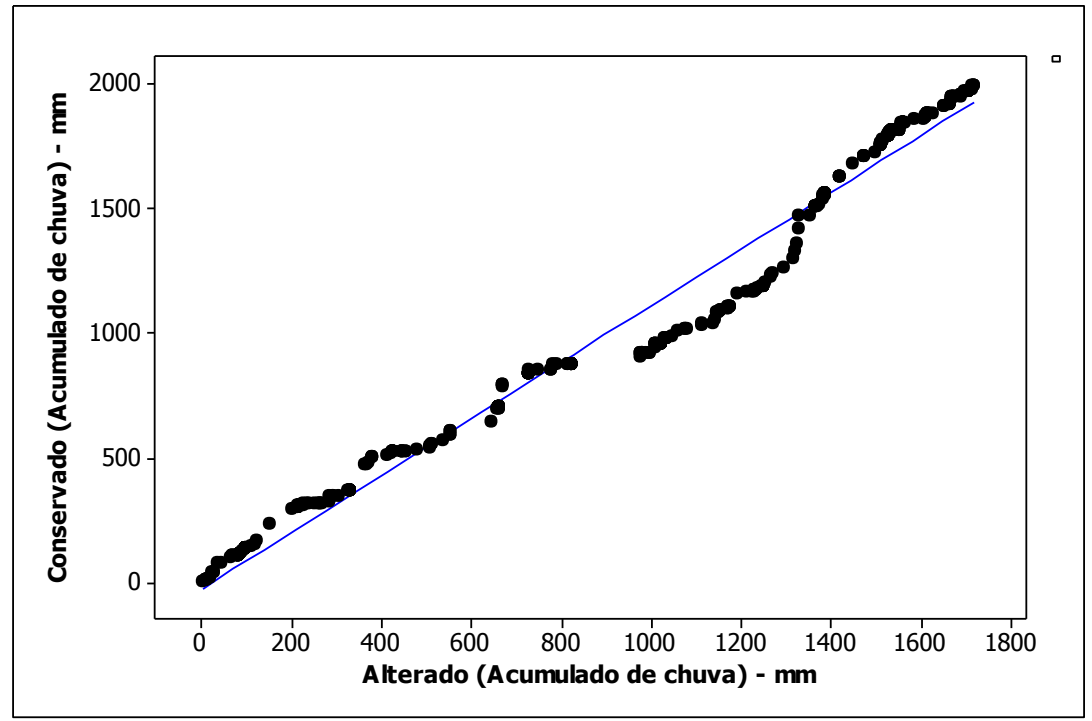

Figura 6. Regressão Linear Simples em escala diária da precipitação acumulada nos manguezais alterado e conservado, na APACIP e no PEIC, respectivamente.

\section{Conclusões}

Considerando-se que manguezais respondem intensamente às forçantes ambientais, o monitoramento do microclima de bosques de mangue tem possibilitado o entendimento das condições ambientais em Unidades de Conservação costeiras de categorias de manejo distintas, no litoral sul de São Paulo. 
A partir do levantamento dos atributos climáticos nos bosques de mangue ao longo do período monitorado pode-se avaliar que o manguezal conservado, localizado na Unidade de Conservação de Proteção Integral Parque Estadual da Ilha do Cardoso apresenta: a) uma maior estabilidade térmica em termos de temperatura máxima, mínima e média do ar e por conseguinte nos valores de amplitude térmica; b) o papel da vegetação é perceptível na (re)distribuição de energia no interior do dossel quando avaliamos os valores de radiação solar global nos bosques de mangue conservado (no PEIC) e alterado (na APACIP); c) O manguezal pode desempenhar importante interação com eventos extremos reduzindo seus efeitos.

Dessa forma, pode-se afirmar que UCs de Proteção Integral tem papel fundamental na manutenção do bom estado de conservação dos manguezais do litoral sul de São Paulo e consequentemente de seus serviços ecossistêmicos relacionados à estabilização do microclima, tais como os elencados acima. Garantir a efetividade de sua gestão, bem como ações de monitoramento é fundamental para os ecossistemas ali instalados.

\section{Agradecimentos}

Os autores agradecem os auxílios financeiros concedidos pelo $\mathrm{CNPq}$, edital Universal (Processos 482819/2013-8 e 445418/2014-1) e bolsa PQ (Emerson Galvani - 303676/2013-2) e pela Fundação Grupo O Boticário, edital Bio\&Clima Lagamar (Processo BL0006_20121) e aos orgãos ICMBio e Fundação Florestal/SMA pelas autorizações para o desenvolvimento da pesquisa realizada na APA CIP e no PEIC, respectivamente.

\section{Bibliografia}

ALONGI, D. M. Present state and future of the world's mangrove forests. Environmental Conservation 29 (3): 331-349. 2002. Foundation for Environmental Conservation.

ALONGI, D. M. Mangrove forests: Resilience, protection from tsunamis, and responses to global climate change. Estuarine, Coastal and Shelf Science. v. 76, p. 1-13. 2008.

ALONGI, D. M. The energetics of mangrove forests. Queensland: Springer Science, 2009. $216 \mathrm{p}$.

BESERRA DE LIMA, N. G.; GALVANI, E. Mangrove Microclimate: A Case Study from Southeastern Brazil. Earth Interactions, v. 17, p. 1, 2013.

CUNHA-LIGNON, M.; KAMPEL, M.; MENGHINI, R.P.; SCHAEFFER-NOVELLI, Y.; CINTRÓN, G.; DAHDOUH-GUEBAS, F., 2011. Mangrove Forests Submitted to Depositional Processes and Salinity Variation Investigated using satellite images and vegetation structure surveys. Journal of Coastal Research, SI 64, v. I, p. 344-348.

CUNHA-LIGNON, M.; ALMEIDA, R.; LIMA, N.G.B.; GALVANI, E.; MENGHINI, R.P.; COELHO-JR., C.; SCHAEFFER-NOVELLI, Y., 2015. Monitoramento de Manguezais: abordagem integrada frente às alterações ambientais. Anais... VIII CBUC - Trabalhos Técnicos, Curitiba, 1-17. 


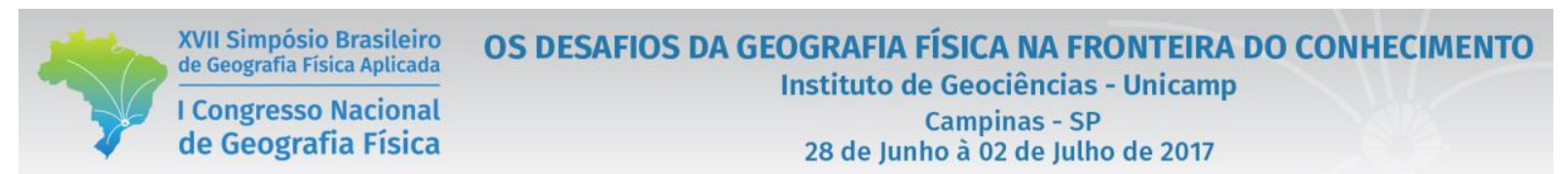

DUKE, N.C.; MEYNECKE, J.-0.; DITTMANN, A.M.; ELLISON, A.M.; AANGER, K.; BERGER, U.; CANNICCI, S.; DIELE, K.; EWEL, K.C.; FIELD, C.D.; KOEDAM, N.; LEE, S.Y.; MARCHAND, C.; NORDHAUS, I.; DAHDOUH-GUEBAS, F., 2007. A world without mangroves? Science, 317: 41-42.

GALVANI, E.; LIMA, N. G. B., Estudos climáticos nas escalas inferiores do clima: manguezais da Barra do Rio Ribeira, Iguape, SP. Revista Mercator, 9 (1), 25-38, 2010.

GIRI, C.; Ochieng, E; TIESZEN, L.L; DUKE, N. Status and distribution of mangrove forests of the world using earth observation satellite data. Global Ecology and Biogeography, 2011. 20, 154-159.

KRAUSS, K.; DOYLE T.; DOYLE, T.; SWARZENSKI, C; FROM, A.; DAY, R.; CONNER, W. Water level observations in mangrove swamps during two hurricanes in Florida. Wetlands, Vol. 29, No. 1, March 2009, pp. $142-149$.

LACAMBRA, C.; SPENCER, T.; MOELLER, I. Tropical coastal ecosystems as coastal defences. ProAct Network, Unitec Kingdom, p. 1-22, 2008.

LIMA, N.G.B. DE, GALVANI, E.; CUNHA-LIGNON, M.. Air temperature and canopy cover of impacted and conserved mangrove ecosystems: a study of a subtropical estuary in Brazil. Journal of Coastal Research, Special Issue No. 65, 2013.

LUGO, A.E.; MEDINA, E; MCGINLEY, K. Issues and challenges of Mangrove conservation in the Anthropocene. Madera y Bosques vol. 20, núm. especial : 11-38 2014

MAGRIS, R.A.; BARRETO, R. Mapping and assessment of protection of mangrove habitats in Brazil. PanAmerican Journal of Aquatic Sciences (2010), 5(4):546-556

MAHIQUES, M.M.; BURONE, L.; FIGUEIRA, R.C.L.; LAVENÉRE-WANDERLEY, A.A.O.; CAPELLARI, B.; ROGACHSKI, C.E.; BARROSO, C.P.; SANTOS, L.A.S.; CORDERO, L.M.; CUSSIOLI, M.C., 2009. Anthropogenic influences in a lagoonal environment: a multiproxy approach at the Valo Grande Mouth, CananéiaIguape System (SE Brazil). Brazilian Journal of Oceanography, 57(4), 325-337.

MAZDA, Y.; WOLANSKI, E; RIDD, P.V. The Role of Physical Processes in Mangrove Environments. Manual for the Preservation and Utilization of Mangrove Ecosystems. TERRAPUB, Tokyo. 2007

MCLVOR et al., 2012 . Reduction of wind and swell waves by mangroves. NCP Report 2012-01.

MEDELLU, C.; BERHIMPON, S. The Influence of Opening on the Gradient and Air Temperature Edge Effects in Mangrove Forests. International Journal of Basic \& Applied Sciences. IJBAS-IJENS Vol: 12 nº: 02.2012.

SCHAEFFER-NOVELLI, Y.; CINTRÓN, G.; Guia para estudo de áreas de manguezal - estrutura, função e flora. São Paulo: Caribbean Ecological Research, 1986.

TARIFA, J. R. Unidades climáticas dos maciços litorâneos da Juréia-Itatins. In: Estação Ecológica Juréia-Itatins: Ambiente Físico, Flora e Fauna. Org. Otavio A.V. Marques; Wânia Duleba. São Paulo: Holos. 2004. p. 42 a 50.

VALIELA, I.; BOWEN, J.L.; YORK, J.K. Mangrove Forests: One of the World's Threatened Major Tropical Environments. BioScience 2001, 51, 807-815.

ZHANG, K.; LIU, H.; LI, Y.; XU, H.; SHEN, J.; RHOME, J.; SMITH III, T. The role of mangroves in attenuating storm surges. Estuarine, Coastal and Shelf Science 102-103 11 - 23, 2012. 